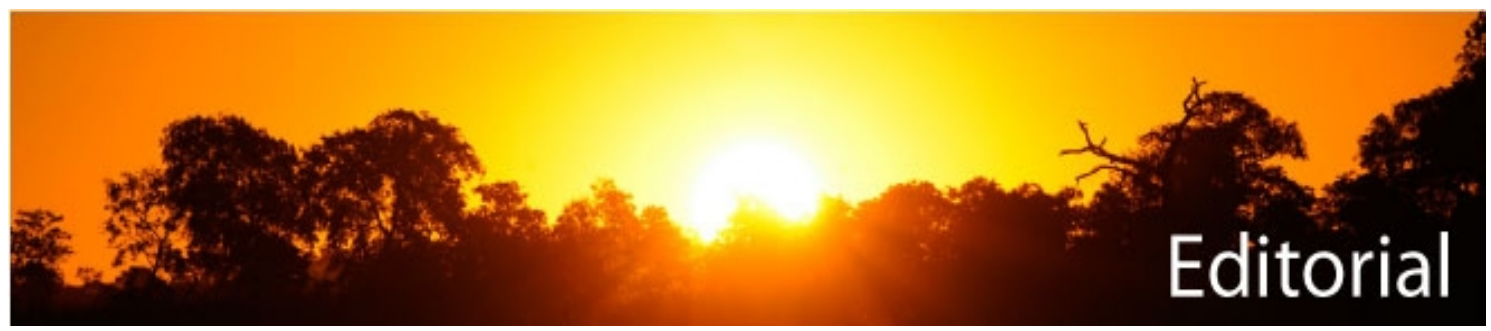

\title{
ÉTICA AMBIENTAL E TECNOLOGIAS APLICÁVEIS AO DESENVOLVIMENTO SUSTENTÁVEL
}

\author{
Jairo Afonso Henkes ${ }^{1}$
}

Ao se publicar a décima edição desta revista científica comemoramos mais de trezentos mil acessos, demonstrando que os artigos, estudos, relatos, editoriais e notícias tem sido fonte de consultas acadêmico e científicas, denotado ainda pelo aumento de citações a trabalhos nela publicados, evidenciando o percurso de um caminho desenvolvido em parceria em busca da produção e disseminação de conhecimentos, técnicas, análises e produtos que tem 0 objetivo de desenvolver de forma sustentável os mais diversos segmentos da sociedade moderna.

Destaca-se neste momento, a importância da transparência e ética nas relações humanas, fato que inclui, e não dispensa, a ética nos estudos e procedimentos ambientais, de forma que estes protejam e recuperem 0 ambiente de forma sustentável, para que não só se pretenda o cumprimento aos regulamentos legais, mas que para que se observem, se desenvolvam, projetos, ações e programas para a proteção ambiental em todas atividades e empreendimentos idealizados pela sociedade, visando o cumprimento dos princípios normativos e de forma clara o desenvolvimento sustentável em sua máxima definição.

No desenrolar das nove edições que antecederam a esta, buscou-se comprovar a afirmativa de que é possível o desenvolvimento econômico e social de forma sustentável, com a manutenção e a melhoria das condições ambientais dos locais onde estão inseridos os empreendimentos, experimentos e as atividades humanas. Melhorar ou manter as condições ambientais nos 
asseguram a possibilidade de projetarmos um melhor horizonte para as futuras gerações, oportunizando a estas a possibilidade de sobrevivência digna e conhecimentos técnico-científicos para delinear novos e melhores rumos para a humanidade e para o planeta.

Esta edição apresenta 20 artigos que tratam de diversas e diferentes questões relativas à gestão e sustentabilidade ambiental, submetidos por pesquisadores de diversas origens, diferentes instituições e organizações, de diferentes realidades sociais e regionais, demonstrando a forma democrática e ética de atuação do Conselho Editorial deste Periódico Científico, que pretende não só disseminar a ética ambiental e as tecnologias aplicáveis ao desenvolvimento sustentável, mas também inferir sobre as realidades existentes em diferentes locais, oportunizando a estes o acesso de forma livre, aberta e gratuita a diversos Recursos Educacionais Abertos - REA, disponibilizados em suas publicações.

Entre os assuntos em pauta destacam-se análises de viabilidade e sustentabilidade na implantação de inovações tecnológicas e ou de processos na área industrial, na agregação de valor, em práticas sustentáveis e de educação ambiental em segmentos distintos. A avaliação da eficácia de microalgas em biorreatores, e da sustentabilidade da gestão de resíduos sólidos urbanos também são objetos desta edição. Diagnósticos de impactos ambientais, avaliação e planejamento de recursos hídricos, assim como análises relativas aos créditos de carbono, envolvendo o uso de MDL Mecanismos de Desenvolvimento Limpo, compreendem outros estudos aqui divulgados.

A relevância e pertinência dos temas abordados nesta edição têm consolidado a Revista Gestão \& Sustentabilidade Ambiental, que nesta edição traz artigos que abordam diversos temas, de diferentes áreas de atuação, tais como: 1. Análise da viabilidade sustentável da instalação de uma linha de patê de palmito, para agregação de valor numa indústria de conserva de palmito. 2 . Análise das práticas de educação ambiental em duas escolas de ensino médio na cidade de juazeiro do Norte no estado do Ceará. 3. A análise de práticas sustentáveis via estudo de caso de empresas do ramo hoteleiro. 4. Viabilidade de implantação de uma caldeira para a cogeração de energia a partir da 
biomassa. 5. Avaliação da eficiência de floculação e ambiental pela recuperação da biomassa de microalgas cultivadas em fotobiorreatores compactos industriais. 6. Avaliação da sustentabilidade na gestão de resíduos sólidos urbanos, com um estudo de caso envolvendo segmentos sociais no município de Feira de Santana, Bahia. 7. Crédito de Carbono, um estudo bibliométrico nos principais periódicos nacionais e internacionais. 8. 0 desenvolvimento de um modelo para avaliar a sustentabilidade nas micro e pequenas empresas. 9. Diagnóstico dos impactos ambientais e proposta de recuperação de uma área urbana degradada, localizada no município de Itumbiara, Goiás. 10. Evidenciação do estado da arte no tema avaliação de contrato de seguro. 11. Evidenciação dos modelos de simulação e técnicas para o planejamento integrado dos sistemas hídricos. 12. Gastos ambientais e níveis de atividades potencialmente poluidoras nas empresas do Índice de Sustentabilidade Empresarial (ISE) da BMF\& Bovespa. 13. Mecanismos de desenvolvimento limpo (MDL) em cooperativas agrícolas, o caso da COOASGO no Mato Grosso do Sul. 14. Medicamentos Antineoplásicos no meio ambiente, a contribuição de um hospital universitário de alta complexidade. 15. O desafio competitivo brasileiro e o Shale Gas norte americano. 16. O desempenho ambiental de companhias brasileiras, uma analise das companhias do ISE. 17. Plano de fechamento de mina, alternativas para reutilização da área impactada. 18. Reciclagem industrial como agente propulsor da preservação de recursos naturais. 19. Proposta de zoneamento ambiental aplicado à Microbacia do Rio Vargem dos Pinheiros, Angelina, Santa Catarina, sul do Brasil. 20. Análise das condições de tráfego e de pavimentação na Microbacia hidrográfica do Córrego do Mineirinho (São Carlos/SP): proposta de alternativas para mobilidade e pavimentação urbana.

A realização de estudos e análises envolvendo a avaliação de seguros e as relações de atividades potencialmente poluidoras $\mathrm{e}$ indicadores de sustentabilidade empresarial, acompanhadas de uma análise do desempenho ambiental de algumas companhias brasileiras, tanto na mineração quanto na prospecção de gás, também fazem parte do escopo da gestão e sustentabilidade ambiental, linhas basilares deste periódico. 
A abordagem importante das questões ambientais no uso e descarte de medicamentos, a reciclagem industrial o zoneamento ambiental são outras áreas cobertas pelo desafio da busca constante de alternativas sustentáveis e factiveis dentro do processo de desenvolvimento sustentável.

$\mathrm{Na}$ Seção Estudos de Caso publicam-se cinco estudos de caso desenvolvidos por acadêmicos de diversos cursos, que trazem à discussão temas como: 1. A implementação de sistemas de Gestão Ambiental no meio empresarial, realizando uma avaliação da utilização da norma ISO 14001, como ferramenta de melhoria de desempenho empresarial, em indústrias no estado de São Paulo. 2. Como se produzir cosméticos de forma mais sustentável. 3. Uma análise da separação e descarte de resíduos sólidos urbanos de modo adequado, sempre com foco nos resíduos sólidos domésticos. 4. Um estudo sobre alternativas para a revitalização do Rio Tietê em São Paulo, como uma opção necessária e viável é outro estudo apresentado. 5. Por derradeiro apresentamos um estudo sobre as barreiras para implantar a logística reversa para aparelhos celulares.

A analisar-se a evolução quantitativa e qualitativa deste periódico, cumpre ressaltar as importantes parcerias institucionais já realizadas com organizações, eventos e institutos de pesquisa e fomento. Estes elementos nos levam a uma condição conceitual relevante, pois já totalizam mais de trezentos e vinte mil acessos à revista e seus conteúdos, com centenas de Gigabytes em donwloads efetivados.

Todavia ela não se realiza em si mesma, pois a sua grandeza está na parceria dos autores, que submetem artigos a este periódico, à nossa equipe de Revisores / Avaliadores, ao nosso Conselho Editorial e a confiança demonstrada não só pelas leituras, mas pelo uso dos estudos aqui desenvolvidos, que estão sendo utilizados na formação de melhores cidadãos, no ensino e na produção de novos conhecimentos.

1 Editor da RG\&SA. Mestre em Agroecossistemas. Especialista em Administração Rural. Engenheiro Agrônomo. Professor do Curso de Administração, do Curso Superior de Tecnologia em Gestão Ambiental e do Programa de Pós Graduação em Gestão Ambiental da Unisul. Email: jairo.henkes@unisul.br 